\title{
LA RESOCIALIZACIÓN EN COLOMBIA: UN FRACASO \\ DE RECURSOS O DE VOLUNTAD
}

Anuario de Derecho N ${ }^{\circ}$ 48-2019 - Año XXXIX - ISSN 0553-0814 Edición anual diciembre 2018-noviembre 2019

\section{LA RESOCIALIZACIÓN EN COLOMBIA: UN FRACASO DE RECURSOS O DE VOLUNTAD}

\author{
Steven David Jaller Merlano ${ }^{1}$ \\ Corporación Universitaria Americana, Colombia \\ E-mail: sdjeller@gmail.com \\ Eliana Lizeth González López ${ }^{1}$ \\ Corporación Universitaria Americana, Colombia \\ E-mail: ligonzalezl@gmail.com
}

\section{RESUMEN}

La finalidad de este artículo es analizar el Concepto de resocialización en Colombia, la aplicación de sus programas y su efectividad, relacionando estos con él, porque del fracaso para alcanzar el objetivo normativo, si bien, es de conocimiento público que la restauración de las personas privadas de la libertad no se refleja en nuestro país como un resultado destacable, nuestra investigación trata de hacer un aporte a esta gran labor de recuperar a estas personas que se equivocaron y tomaron la ruta del delito, por medio de un centro propio de la institución que cuente con actividades laborales y de apoyo como; Call Center, Tele trabajo y la vinculación de la familia dentro de este proceso, desde un enfoque de experiencias significativas que hayan producido efectos positivos dentro de este contexto y que permita acercarse más a la resocialización de esta población.

Palabras Clave: Resocialización, fines de la pena, discriminación, falta de recursos, reincidencia, hacinamiento, voluntad.

\section{ABSTRACT}

The purpose of this article is to analyze the concept of resocialization in Colombia, the application of its programs and their effectiveness, relating these with concept of resocialization, because of the failure to reach the normative objective, even though, it is public knowledge that the restoration of private persons of freedom is not reflected in our country as a remarkable result, our research tries to make a contribution to this great work of recovering to these people who were wrong and took the path of crime, through of a center of the institution that has work activities and support as; Call Center, Telework and family bonding within this process, from a focus of significant experiences that have produced positive effects in this context and that allows get closer to the resocialization of this population.

\section{KEYWORDS}

Resocialization, purposes of punishment, discrimination, lack of resources, recidivism, injury, volition.

1 Estudiantes del último Semestre del programa de Derecho, Facultad de Humanidades y Ciencias Sociales de la Corporación Universitaria Americana de Medellín - Colombia, Participantes en el Semillero de Investigación Eureka. 


\section{Introducción}

Alguna vez nos hemos preguntado ¿Qué hacen las personas después de salir de la cárcel? ¿Salen con un enfoque diferente? ¿La duración de su estadía en la cárcel es el tiempo que tardan en ser restaurados y aptos para la sociedad? Sí y No. Puede ser difícil impulsar el cambio en una persona, ahora imagina como seria tratar de hacerlo con miles de ellas, ¿Es esto posible? Aunque existan programas internos en los centros penitenciarios que permiten convertir al "Malo en Bueno", o por lo menos ese es el objetivo, su estadía en estos lugares puede convertir al "Bueno en Malo". Se estarán preguntando ¿Cómo que al Bueno en Malo? Si están allá es porque son Malos, la respuesta es No. Es desacertado afirmar que todas las personas privadas de la libertad son "Malas": este concepto es muy usado desde el punto de vista de la sociedad y tal vez el menos degradante del ser humano para describir a las personas que comenten o cometieron delitos. Retomando, muchas de estas personas no cometieron el injusto penal, pero que por diversas situaciones, algunas relacionadas con la mediocridad de la profesión del abogado que no tiene un horizonte marcado y no pelea hasta el final, sino que simplemente le dice a su protegido "allánese que le va mejor así". Es decir, son culpables en el proceso, pero no en el mundo fenoménico. Regresando al tema de volver Bueno al Malo, este primer enfoque es el énfasis y el que nos interesa, ya que la misión es que no vuelvan a cometer delitos.

A ese proceso de transformación se le llama Resocialización y es de carácter fundamental saber que este es una segunda oportunidad, es decir es una segunda socialización, que tienen las personas privadas de la libertad para volver a ser parte de un grupo social armónico al cual dejaron de pertenecer al momento de ser objeto de investigación penal por una conducta punible en la que fueron encontrados culpables y que por consecuencia acarrea la imposición de una pena privativa de la libertad, que de una u otra manera marca su trayectoria en toda su vida dentro de la sociedad, por falta la de aceptación de ella, que pueden ser traducidas al simple mensaje de una frase "El que es, no deja de ser" y que por ende en el contexto social seguirá representando peligro, zozobra, entre otra variedad de expresiones que generan como efecto el apartarse y rechazar de primer plano a alguien que fue penado.

Ahora ya sabemos o tenemos material para responder a esas preguntas. Pero ahora, si las personas que salen de la cárcel no cambian o no están saliendo con ese enfoque diferente la pregunta más importante aquí es.

\section{¿Qué Factores impiden que las personas privadas de la libertad alcancen la resocialización?}

Cuando a una persona le es impuesta la pena de prisión y esta no ha sido beneficiada con alguno de los mecanismos alternativos o sustitutivos que permitan su excarcelación, porque no son procedentes, aquella deberá ser recluida en un establecimiento de reclusión en la calidad de condenada. Para la ley penal desde este momento -hace parte de la fase de ejecución de la pena- y 
se tendrá en cuenta la prevención especial y la reinserción social, De que trata el enciso $2^{\circ}$ del Artículo 4 de la Ley 599 de 2000, siendo el objetivo principal la resocialización.

El concepto de resocialización adopta un estándar que busca la rehabilitación del penado, con esto se pretende que el individuo no vuelva a delinquir en el futuro (Hernández, 2017), para lo cual entran a jugar un papel importante los programas de resocialización y su correcta aplicación. El sentido de estos programas apuntan a que las personas privadas de la libertad se contextualicen con la sociedad por medio de actividades que tienen los siguientes componentes: "bienestar social del interno, educación, deporte y cultura, emprenderismo y trabajo con enfoque diferencial". (Ley $\mathrm{N}^{\circ}$ 1709 de 2014)

La Corte Constitucional ha señalado que:

"Es imperioso recordar que el esfuerzo por la resocialización del delincuente y por su incorporación a la vida en sociedad después de su castigo, se traduce en beneficios para la comunidad. Por el contrario abandonar tal enfoque hace que el sistema penitenciario y carcelario se convierta en un sistema multiplicador de conflictos que genera más y "mejores" delincuentes (la cárcel como universidad del delito), lo que finalmente termina siendo más costoso para el conglomerado social" (Vélez y Medina,2016). ${ }^{2}$

En esta misma providencia se enfatiza más adelante que si no se alcanza la resocialización real de los condenados no se reduce la reincidencia (Hernández, 2017).

La idea de castigo que se relaciona a la labor de recuperar esa población que siguió el camino del delito y convertirlos en personas de bien, que puedan volver a ocupar sus posiciones dentro de la sociedad; de padres, madres, hijos, hermanos, etc. Es la Prevención Especial Positiva, esta una figura jurídica que alude a los efectos que tendría la aplicación de una pena en el individuo a la que va dirigida. Alejándose de toda pena desproporcionada y sin fines restauradores que no permitan cumplir con los fines legales -prevención especial y reinserción social- como lo expresamos inicialmente.

Para que se cumpla el mandato legal rehabilitador las prisiones deben ofrecer unas condiciones de vida mínimas, que se desprenden propiamente del Derecho Internacional Humanitario y las interpretaciones de sus entes principales como la Comisión Interamericana de Derechos Humanos. Siendo estos de imperativo cumplimiento (Hernández, 2017).

Dichos requerimientos los relacionaremos a continuación:

2 En esta providencia la Corte se ha pronunciado mediante las Sentencias T-153 de 1998 y T-388 de 2013, en las cuales declaró la existencia de un Estado de Cosas Inconstitucionales "en las prisiones" y en el "Sistema Penitenciario y Carcelario". 
- Derecho de los reclusos a ser ubicados en locales higiénicos y dignos.

- Derecho de los reclusos a contar con instalaciones sanitarias adecuadas a sus necesidades y al decoro mínimo propio de su dignidad humana.

- Derecho de los reclusos a recibir ropa digna para su vestido personal.

- Derecho de los reclusos a tener una cama individual con su ropa de cama correspondiente en condiciones higiénicas.

- Derecho de los reclusos a contar con alimentación y agua potable, suficiente y adecuada.

- Derecho a tener una adecuada iluminación y ventilación del sitio de reclusión.

- Derecho a recibir implementos necesarios para el debido aseo personal.

- Derecho de los reclusos a practicar, cuando ello sea posible, un ejercicio diariamente al aire libre.

- Derecho de los reclusos a ser examinados por médicos a su ingreso al establecimiento y cuando así se requiera.

- Derecho de los reclusos a recibir atención médica constante y diligente.

- Prohibición de las penas corporales y demás penas crueles, inhumanas o degradantes.

- Derecho de los reclusos a acceder a material de lectura.

- Derechos religiosos de los reclusos.

Después de observar cada uno de estos requerimientos de carácter obligatorio nos surgirá otra pregunta ¿Cuáles son las condiciones vida de las personas privadas de la libertad en las prisiones de Colombia?

\section{Condiciones de vida en las prisiones de Colombia}

Además de infraestructuras deficientes que son la realidad de la mayoría de prisiones en Colombia, si no todas, el personal disponible para trabajar en estos planteles es bastante bajo en relación al número de internos, datos que dan claridad de la dificultad para garantizar una adecuada estadía y un trato digno a todas las personas que se encuentran recluidas en las prisiones de nuestro país. Principio que tiene gran auge dentro del Derecho y nuestro sistema Jurídico: la Dignidad Humana.

Las violaciones de dicho principio parten de la imposibilidad de cumplir con los requerimientos obligatorios que relacionamos anteriormente, por nada más que falta de recursos planeación y logística. La cantidad de delincuencia equivalente al gran número de penados que al ser intramural no es posible contrarrestar desde una realidad de recursos muy limitados con los que cuenta el Sistema Nacional Penitenciario y Carcelario; hecho que no justifica las condiciones de vida que vulneren derechos fundamentales de los penados intramural como lo expresa el artículo $4^{\circ}$ enciso $3^{\text {o }}$ de la ley 1709 .

La misma Ley en su artículo 8 enciso cuarto: "Se faculta al Ministerio de Hacienda y Crédito Público asignar los recursos suficientes a la Uspec para la creación, organización y mantenimiento de los establecimientos de reclusión”. ¿Qué pasa con esos recursos? A veces 
producto de la corrupción entre varias situaciones principalmente esta que no permite que se esté trámite legal.

\section{Población Penitenciaria}

Un informe estadístico del mes de septiembre de 2018 del INPEC muestra el total de la población carcelaria hasta dicha fecha, con las diferentes modalidades de ubicación: intramural, domiciliaria y vigilancia electrónica, entre otros datos relacionados a continuación en la tabla 1.

"Al cierre del tercer trimestre de 2018, en los diferentes centros penitenciarios y carcelarios del país se encontraban 186.175 personas privadas de la libertad. De acuerdo a la entidad que debe responde por su custodia y vigilancia se tiene:

- $\quad$ Instituto Nacional Penitenciario y Carcelario-Inpec 98,2\%(183.506).

- $\quad$ Establecimientos de Reclusión del Orden Municipal 1,4\%(2.631).

- $\quad$ Establecimientos de Reclusión de la Fuerza Pública 0,4\%(801).

La población reclusa a cargo del Inpec (183.506), se encuentra bajo las siguientes modalidades de ubicación:

- En Establecimiento de Reclusión del Orden Nacional -ERON (intramuros), 64,9\%(119.125).

- $\quad$ En detención y prisión domiciliaria, 32,6\% (59.765 - incluye 226 Gestores de Paz).

- $\quad$ Con vigilancia electrónica, 2,5\%(4.616).

Tabla 1. Población con medida de aseguramiento en Colombia

\begin{tabular}{|c|c|c|c|c|}
\hline \multirow{2}{*}{$\begin{array}{l}\text { Entidades a cargo de la } \\
\text { custodia y vigilancia de los } \\
\text { reclusos(as) }\end{array}$} & \multirow[b]{2}{*}{ Ubicación } & \multirow[b]{2}{*}{ Reclusos(as) } & \multicolumn{2}{|c|}{ Participación } \\
\hline & & & $\begin{array}{l}\text { Con respecto al total } \\
\text { de la población a } \\
\text { cargo de la entidad }\end{array}$ & \begin{tabular}{|c|} 
Con respecto al \\
total de la población \\
reclusa del país
\end{tabular} \\
\hline \multirow{4}{*}{ INPEC } & $\begin{array}{l}\text { Establecimientos de Reclusión del Orden } \\
\text { Nacional -ERON }\end{array}$ & 119.125 & $64,9 \%$ & $63,7 \%$ \\
\hline & Domiciliaria (incluye 226 Gestores de Paz) & 59.765 & $32,6 \%$ & $32,0 \%$ \\
\hline & Vigilancia Electrónica & 4.616 & $2,5 \%$ & $2,5 \%$ \\
\hline & Subtotal INPEC & 183.506 & $100,0 \%$ & $98,2 \%$ \\
\hline \multirow{3}{*}{$\begin{array}{c}\text { OTRAS } \\
\text { ENTIDADES }\end{array}$} & Establecimientos Municipales & 2.631 & $76,7 \%$ & $1,4 \%$ \\
\hline & Establecimientos Fuerza Pública & 801 & $23,3 \%$ & $0,4 \%$ \\
\hline & Subtotal otros establecimientos & 3.432 & $100,0 \%$ & $1,8 \%$ \\
\hline \multicolumn{2}{|c|}{ Total población reclusa país } & 186.938 & & $100,0 \%$ \\
\hline
\end{tabular}

Fuente: GEDIP - Septiembre 2018 
La población reclusa en Colombia se incrementó de agosto a septiembre en 0,4\% (763 personas). La población reclusa a cargo del Instituto en todas las modalidades de privación de la libertad (183.506), aumentó 0,4\% (774 personas) con respecto al mes de anterior (182.732)"” (INPEC, 2018, p.).

El número de personas que se encuentra recluido en prisiones a nivel país es 119,125. A pesar de que en los diferentes estudios que dan las estadísticas mes a mes y anuales de estos datos, se presentan diversas variaciones en cuanto a los porcentajes de aumento y disminución de la población que se encuentra privada de la libertad. La tendencia en Colombia es la del incremento, información que se relaciona en las tablas 2 y 3.

"La evolución de la población intramural a cargo del Instituto en los últimos cinco años muestra que el año 2014 cerró con una considerable caída en el número de internos(as) de 5,3\% (-6.409) producto de la aplicación de la Ley 1709 de 2014; sin embargo, en 2015, una vez menguado el impacto de la ley antes mencionada, la población interna se estabiliza y retoma su tendencia creciente, al punto de culminar el año con un incremento porcentual del 6,0\% (6.821). En 2016 se observa una tendencia decreciente, cerrando con una variación porcentual de -1,6\% (-1.912). En 2017 la variación continua en la misma línea, concluyendo en -3,2\% (3.782 personas menos). En septiembre de 2018 se observa incremento de 3,8\% (4.375 internos(as) más) (INPEC, 2018, p.).

Tabla 2.

Población reclusa a cargo del Inpec 2013 - 2018: Tasa por 100 mil habitantes

\begin{tabular}{|c|c|c|c|c|c|c|}
\hline \multirow[t]{2}{*}{ Año } & \multirow{2}{*}{$\begin{array}{l}\text { Población } \\
\text { colombiana }\end{array}$} & \multirow{2}{*}{$\begin{array}{c}\text { Población reclusa } \\
\text { Inpec(intramural, } \\
\text { domiciliaria y con vig. . } \\
\text { electrónica) }\end{array}$} & \multicolumn{2}{|c|}{$\begin{array}{l}\text { Variación anual población } \\
\text { reclusa }\end{array}$} & \multirow{2}{*}{$\begin{array}{c}\text { Participación } \\
\text { nacional }\end{array}$} & \multirow{2}{*}{$\begin{array}{c}\text { Tasa población } \\
\text { reclusapor100mi } \\
\text { habitantes }\end{array}$} \\
\hline & & & Absoluta & Relativa & & \\
\hline 2013 & 47.121 .089 & 151.368 & 10.639 & $7,6 \%$ & $0,3 \%$ & 321 \\
\hline 2014 & 47.661 .787 & 153.998 & 2.630 & $1,7 \%$ & $0,3 \%$ & 323 \\
\hline 2015 & 48.401 .701 & 169.662 & 15.664 & $10,2 \%$ & $0,4 \%$ & 351 \\
\hline 2016 & 48.747 .708 & 175.336 & 5.674 & $3,3 \%$ & $0,4 \%$ & 360 \\
\hline 2017 & 49.582 .835 & 178.397 & 3.061 & $1,7 \%$ & $0,4 \%$ & 360 \\
\hline 2018 & 49.834 .240 & 183.506 & 5.109 & $2,9 \%$ & $0,4 \%$ & 368 \\
\hline
\end{tabular}

Fuente: (INPEC, 2018) 
Tabla 3.

Población reclusa intramural a cargo del Inpec 2013 - 2018: Tasa por 100 mil habitantes

\begin{tabular}{|c|c|c|c|c|c|c|}
\multirow{2}{*}{ Año } & $\begin{array}{c}\text { Población } \\
\text { colombiana }\end{array}$ & $\begin{array}{c}\text { Población reclusa } \\
\text { intramural Inpec }\end{array}$ & $\begin{array}{c}\text { Variación anual } \\
\text { población } \\
\text { reclusa } \\
\text { intramural }\end{array}$ & $\begin{array}{c}\text { Participación } \\
\text { nacional }\end{array}$ & $\begin{array}{c}\text { Tasa población } \\
\text { intramuralporl00milhabitantes }\end{array}$ \\
\cline { 1 - 5 } 2013 & 47.121 .089 & 120.032 & 6.148 & $5,4 \%$ & $0,3 \%$ & 255 \\
\hline 2014 & 47.661 .787 & 113.623 & -6.409 & $-5,3 \%$ & $0,2 \%$ & 238 \\
\hline 2015 & 48.401 .701 & 120.444 & 6.821 & $6,0 \%$ & $0,2 \%$ & 249 \\
\hline 2016 & 48.747 .708 & 118.532 & -1.912 & $-1,6 \%$ & $0,2 \%$ & 243 \\
\hline 2017 & 49.582 .835 & 114.750 & -3.782 & $-3,2 \%$ & $0,2 \%$ & 231 \\
\hline
\end{tabular}

Fuente: (INPEC, 2018)

Uno de los efectos que se presenta al surgir ese incremento que de la población privada de la libertad es el hacinamiento concepto que es una realidad en nuestras prisiones, desde personas que duermen en el suelo de las celdas, en el suelo de los pasillos, colgados con hamacas o a la altura del techo en tablas que ellos mismos organizan como sus dormitorios e incluso en los baños lugares de poca higiene y olores fuertes.

Para algunos estará bien que la pasen mal, ya que por hacer un mal fue que llegaron a una prisión, aunque lejos de todo trato inhumano el principio de la Dignidad Humana no es compatible con ninguna de estas condiciones en las que conviven los internos en nuestras cárceles, factores que se relacionan directamente con la falta de centros penitenciarios el mantenimiento de los mismos, el compromiso de los entes administrativos encargados de proveer estos recursos y del mismo Estado y la sociedad, el primero por no contar con la fuerza o recurso suficiente como para controlar práctica de actividades no permitidas por la ley con el apoyo de la fuerza pública, porque esta es insuficiente. No hay para colocar a un policía en cada sector y lugares que faciliten la comisión de delitos, ya que una calle iluminada patrullas bien distribuidas instituciones no contaminadas de la corrupción, sería un gran aporte del Estado pero como esto es toma y dame la sociedad debe tener más compromiso desde su cultura, no podemos dejar que nuestros hijos el futuro de nuestro país tengan o apoyen ideologías paganas que inciten a delinquir, todo esto viene desde la casa ya que los delitos, está comprobado, no solo se presentan en la clase social de bajos recursos, sino que también en la clase social alta y los más escandalosos se dan en la comunidad administradora de nuestro país.

De acá nace mi confrontación entre la voluntad o falta de recursos, que podemos aducir la a la comisión de los delitos y la situación del Sistema Nacional Penitenciario y Carcelario, del porque 
fracasan los fines punitivos, porque las personas no se re-socializan, al principio comentábamos que para esto deben existir las condiciones de vida mínima dentro de estos centros penitenciarios, aunque desde la vista interior y siendo cierto los programas de resocialización se brindan sin excepciones a todos los internos y ellos los rechazan o la mayoría lo hacen, esto según manifestaciones de algunos miembros del INPEC y algunas personas creen que el que no cambia es porque no quiere, pero ahora que creen ustedes ¿Será la cura o la forma de brindarla? Alguien que tiene problemas, porque en general las personas que están privadas de la libertad en su mayoría tienen problemas para encajar en una vida social sin cometer delitos como o desde que óptica pueden apegarse a métodos que no les incentiven. El enfermo no se cura solo. No es posible y menos desde sus condiciones de vida, aunque no negamos que la voluntad sea un elemento esencial del cambio "el querer es poder" y en realidad algunas personas lo han conseguido, han alcanzado su restauración y por ende la resocialización. Pero ¿Qué pasa con los demás entonces? ¿Qué ven los que pueden y quieren en estos programas, que los que no quieren no ven? No será mejor que intentemos colocar esa visión en los otros, lográndolo sería una forma de tener mejores resultados y con actividades propias, idóneas para conseguirlo. Sé que es posible y la voluntad cambia si las condiciones cambian.

Nuestra institución por medio de este proyecto tiene planteado crear un centro propio de la Universidad que cuente con infraestructuras aptas para tales actividades realizadas por los internos como: Call Center, Tele trabajo y por supuesto incluir a la familia dentro de este proceso, ya que es de vital importancia este apoyo que motiva, las garantías que brindan probabilidades de resultados positivos son la recopilación de experiencias significativas, es decir probar con métodos implementados por alguien más que fueron eficaces y efectivos, teniendo como motor principalmente la familia. Recordemos que el compromiso es de todos y esas personas que hoy están allá, algún día vieron la vida desde la libertad y sé que quieren volver a hacerlo. No puede ser reproche social el hecho de que alguien que se equivoque, cambie; por lo tanto, no es prudente ni humano discriminarlos, ya que cualquiera se puede equivocar y es de seres humanos cometer errores.

\section{Conclusiones}

El fracaso de la resocialización en Colombia no se debe al desinterés de los internos en los programas de los centros penitenciarios, sino que es más por la forma en la que llegan éstos a ellos, y en qué condiciones ellos las reciben. Esta afirmación se realiza tomando como referencia los trabajos realizados por voluntarios gestores de segundas oportunidades y defensores de los derechos de la población carcelaria de Colombia. Para ello, utilizan didáctica, talleres y recreación entre otras actividades, que les permiten a los internos tomar conciencia acerca de la importancia que tiene el abandonar la conducta delictiva y aportar a la sociedad. 


\section{Referencias}

INSTITUTO NACIONAL PENITENCIARIO DE COLOMBIA - INPEC. (2018). Informe Estadístico del mes de septiembre de 2018. Recuperado de http://www.inpec.gov.co

Hernández, N. (2017). El Fracaso de la resocialización en Colombia. Revista de derecho, Universidad del Norte, (49), 1-41.

Vélez S., Escobar M., (2016). Sentencia de la Corte Constitucional T-762 de 2015, de dieciséis (16) de diciembre de dos mil quince (2015), sobre estado de cosas inconstitucional en el sistema penitenciario y carcelario en Colombia. M.P. Gloria Stella Ortiz Delgado. Revista Nuevo Foro Penal, Universidad EAFIT,

Congreso de la República de Colombia. (2014). Ley 1709, Bogotá, Colombia, 20 de enero de 2014. Artículo 102 programas de resocialización de 2014.

Congreso de la República de Colombia. (2000). Ley 599, Bogotá, Colombia, 24 de julio de 2000, artículo $4^{\circ}$, funciones de la pena.

Congreso de la República de Colombia. (1993). Ley 65. Bogotá, Colombia, 19 de agosto de 1993. Artículo $9^{\circ}$. Funciones y finalidad de la pena y de las medidas de seguridad, Artículo 10, finalidad del tratamiento penitenciario.

Artículo recibido: 9 de diciembre de 2018

Aprobado: 15 de diciembre de 2018 
